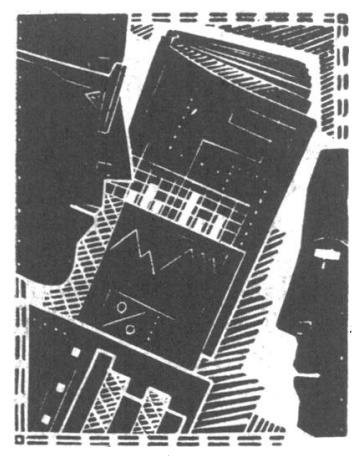

THIS WEEK . .

- In the first article fennings describes how, when outpatients' appointments were arranged by him according to his perception of the patients' needs, rather than according to the current practice of spacing appointments at constant intervals, mean waiting time was reduced by about 30 minutes. He concludes that this improves efficiency, but states that although the new system was readily implemented, it may not be suitable for use in all types of hospital clinics.
- In the second article Dr Gore et al estimate the possible increases in transplantable organs from brain stem dead potential donors from data from the confidential audit of all deaths in intensive care units in England and assess the effectiveness of a publicity campaign in increasing the numbers of offered donors and actual donations.

- In the commissioned article Dr Richards outlines the role of the newly introduced medical audit advisory groups.

\title{
Audit of a new appointments system in a hospital outpatient clinic
}

\author{
M Jennings
}

\section{Abstract}

Objective-To assess the effect of a new appointments system on patients' waiting time.

Design-Replacement of an existing system of regularly spaced appointments at 10 minute intervals with one in which the doctor arranged appointments according to his perception of individual patients' requirements, from December 1988 to June 1989.

Setting-One general medical outpatient clinic.

Patients-All (436) patients under regular review with fixed appointment times during six months; those arriving for blood testing before the start of the clinic and those requiring ambulance transport were excluded.

Main outcome measures-Mean waiting time (mean of difference between appointment time and start of consultation), maximum waiting time, number of patients, and total duration of clinics.

Results - Mean waiting time was reduced by about 30 minutes (from 39.6 to 9.5 mins) over the six months. There was no change in the number of patients attending (mean $15.8 \mathrm{v} 15.4$ ) or the duration of the clinics (mean $187 v 160$ mins).

Conclusion-Efficiency was improved by simple adjustment to the appointments system used in the hospital outpatient clinic.

\section{Introduction}

Patients often spend a long time waiting to see doctors, and time wasted in this way represents an economic cost. A reduction in waiting time could thus improve quality of care and efficiency. The aim of this study was to observe the effect on waiting time of allowing the doctor to arrange his outpatient clinic appointments.

\section{Patients and methods}

The outpatient clinic in which the study was conducted was attended by patients with various general medical conditions. They had all been seen at least once previously, and there were no new referrals. The clinic was held once a week. Individual appointments were arranged by the clerical staff and were spaced at 10 minute intervals. Two groups of patients did not have fixed appointment times: those who arrived before the clinic started for a blood sample to be taken and those who required ambulance transport to and from the hospital.

I changed my appointments system so that all appointments were made by myself. At the end of each consultation I arranged the next appointment by referring to my appointments book. The timing of future appointments was adjusted according to the amount of time I thought that I would need with each patient. I requested that no appointment be made without prior discussion with me. Whenever possible, investigations were done after the consultation, and if any action needed to be taken on the basis of the results this was indicated in the letter to the general practitioner.

The waiting time was taken as the difference between the appointment time and the time I saw the patient. This was recorded by the clinic nurse for all patients with fixed appointment times. The maximum waiting time experienced by any patient, the number of patients attending, and the total duration of each clinic were also noted.

\section{Results}

The new system was introduced in December 1988, and the mean waiting time for patients attending the clinic fell during the subsequent six months (table). The maximum waiting time was also reduced, but the number of patients seen and the total duration of the clinic changed little.

The mean waiting time for the first three patients in each clinic was $7 \cdot 6$ min during December 1988 and 5.4 min in June 1989. The corresponding times for the last three patients were $47 \cdot 6 \mathrm{~min}$ and $17 \cdot 2 \mathrm{~min}$ respectively.

\section{Discussion}

Harrison found that patients' assessments of how much time they needed with the doctor were sufficiently accurate to enable the introduction of a flexible appointments system in general practice, and as a result patients spent less time waiting to see the doctor. ${ }^{1}$ My study showed that the average waiting time for patients attending a hospital clinic may be reduced by giving the doctor responsibility for arranging his own appointments.

Because consultations vary in length a rigid system in which appointments are spaced at regular intervals is 
probably inappropriate. Although patients at the end of the clinic still tended to wait longer than those with earlier appointments, the new system also reduced this inequity.

Few problems were encountered in implementing the new appointments system. Such a system, however, may not be appropriate for haematology and diabeties

Effect of new appointments system on waiting times and number of patients seen, December 1988-7une 1989

\begin{tabular}{lcccc}
\hline Month & $\begin{array}{c}\text { Mean waiting time } \\
\text { (mins) }\end{array}$ & $\begin{array}{c}\text { Mean maximum waiting } \\
\text { time (mins) }\end{array}$ & $\begin{array}{c}\text { Mean No of patients } \\
\text { per clinic }\end{array}$ & $\begin{array}{c}\text { Mean total clinic } \\
\text { duration (mins) }\end{array}$ \\
\hline December 1988 & $39 \cdot 6$ & $78 \cdot 8$ & $15 \cdot 8$ & 187 \\
January 1989 & $41 \cdot 4$ & $61 \cdot 3$ & $12 \cdot 2$ & 169 \\
February 1989 & $28 \cdot 6$ & $48 \cdot 4$ & $14 \cdot 6$ & 185 \\
March 1989 & $10 \cdot 9$ & $47 \cdot 6$ & $14 \cdot 5$ & 186 \\
April 1989 & $12 \cdot 7$ & $48 \cdot 7$ & $14 \cdot 2$ & 168 \\
May 1989 & $8 \cdot 2$ & $38 \cdot 2$ & $15 \cdot 0$ & 160 \\
June 1989 & $9 \cdot 5$ & $37 \cdot 1$ & $15 \cdot 4$ & \\
\hline
\end{tabular}

clinics, when a blood test is usually required before the consultation, or if a high proportion of patients require ambulance transport.

From the economic point of view a reduction in patients' waiting time represents a cost saving. As there was no appreciable change in either the total duration of the clinics or the number of patients seen it is unlikely that the time costs had merely been transferred to the doctor. It seems reasonable to conclude that a reduction in waiting time for patients may result in improvements in efficiency.

I thank Mrs I Hall, nursing auxiliary, for her help with this study.

1 Harrison AT. Appointment systems: feasibility study of a new approach. BMf 1987;294:1465-6.

(Accepted 15 August 1990)
MRC Biostatistics Unit, Cambridge CB2 2BW Sheila M Gore, PHD, senior statistician

Organ Grafting Unit, Royal Victoria Infirmary, Newcastle upon Tyne NE1 4LP

R M Ross Taylor, CHM, consultant surgeon

Thoracic Surgical Unit, Papworth Hospital, Cambridge CB3 8RE John Wallwork, FRCSED, consultant cardiothoracic surgeon

Correspondence to: Dr Gore.

BMF 1991;302:149-53

\title{
Availability of transplantable organs from brain stem dead donors in intensive care units
}

\author{
Sheila M Gore, R M Ross Taylor, John Wallwork
}

\begin{abstract}
Objective-By audit from January to June 1989 to quantify, separately for hearts, kidneys, liver, lungs and corneas, the possible increases in transplantable organs from brain stem dead potential donors in intensive care units and to compare them with the increases achieved in October-November 1989, during intense, national publicity about transplantation.
\end{abstract}

Design-Prospective audit of all deaths in intensive care units in England from 1 January to 30 June 1989 and subsequent case study of the impact of publicity on offers and donations during OctoberNovember 1989.

Setting -15 regional and special health authorities in England.

Patients - 5803 patients dying in intensive care units, of whom 497 were confirmed as brain stem dead and had no general medical contraindication to organ donation.

Main outcome measures-Organ specific suitability for transplantation (as reported by intensive care units); consent for donation of specific suitable organs; and procurement of specific organs reported as suitable for transplantation and offered.

Results-In the $497(8.6 \%)$ brain stem dead potential donors we estimated the organ specific suitability for heart as $63 \%$, kidneys $95 \%$, liver $70 \%$, lungs $29 \%$, and corneas $91 \%$. Refusal of relatives $(30 \%)$ accounted for major losses of suitable organs of all types. For kidneys the loss was equivalent to $44 \%$ of brain stem dead actual kidney donors. No discussion of organ donation was the second most important reason for missed kidney donors, the loss being equivalent to $10 \%$ of brain stem dead actual donors. Non-procurement or difficulties with allocating organs was the second most notable cause of missed suitable liver and lung donors; $29 \%(55)$ of the offered total of 189 liver donors and $27 \%$ (21) of 78 offered suitable lung donors in six months. Non-procurement of suitable, offered organs was rare for kidneys and modest, of the order of $13 \%$ and $10 \%$ respectively, for heart and corneas. Corneal donation from brain stem dead potential donors might be improved nearly as much (that is, a $78 \%$ increase in brain stem dead actual corneal donors) by specific measures to promote corneal donation when other organs are offered as by reducing the overall refusal rate. Restricted offers, non-procurement, and no discussion of donation accounted for nearly equal numbers of lost donations of hearts (each equivalent to $15 \%$ of donated hearts). During October-November 1989 when there was intense, positive publicity about transplantation the rates of refusal and non-discussion fell compared with during January-June $(22 \%, 36 / 163 v 30 \%, 138 / 460$; $7 \%, 33 / 497 v 2 \%, 4 / 167$ respectively). Offers of suitable donors increased significantly $(\mathbf{p}<0.02)$ compared with the first six months of 1989 , most notably for heart donors $(80 v 60.1$ expected) and kidney donors (122 $v 102 \cdot 1$ expected) but only for kidneys was there a noticeable $17 \%$ increase in actual donors (118 actual audited donors $v 100.8$ expected donors; $p=0.09)$.

Conclusions-Four strategies to increase the supply of transplantable organs from brain stem dead potential donors in intensive care units were identified: $(a)$ reducing refusal of relatives $(b)$ avoiding non-procurement of actually suitable organs (by logistical initiatives) and deterioration of initially suitable organs (by donor care initiatives); (c) converting restricted offers to unrestricted offers; and (d) ensuring discussion with families. Early referral to the transplant team or coordinator gives time for discussion about donor care and agreement on medical suitability for donation of specific organs. Solving some of the logistical problems of nonprocurement may be a prerequisite for increased offers to be translated into increased donations. The impact of publicity therefore needs to be measured on offers of suitable donors as well as by actual donations.

\section{Introduction}

Confidential audit of all deaths in intensive care units in England (except coronary care only units and neonatal intensive care units) was initiated by the Department of Health after a recommendation by the Working Party on the Supply of Donor Organs for Transplantation.' It gave estimates of 1700 possible brain stem deaths and 1200 confirmed brain 